\title{
The liminal space palliative care volunteers occupy and their roles within it: a qualitative study
}

\section{Steven Vanderstichelen, ${ }^{1,2}$ Joachim Cohen, ${ }^{1}$ Yanna Van Wesemael, ${ }^{3}$ Luc Deliens, ${ }^{1,2}$ Kenneth Chambaere ${ }^{1,2}$}

\begin{abstract}
${ }^{1}$ End-of-Life Care Research Group, Vrije Universiteit Brussel (VUB) \& Ghent University, Ghent, Belgium

${ }^{2}$ Department of Public Health and Primary Care, Ghent University, Ghent, Belgium ${ }^{3}$ Palliabru, Brussels, Belgium
\end{abstract}

\section{Correspondence to}

Steven Vanderstichelen, Endof-Life Care Research Group, Vrije Universiteit Brussel (VUB) \& Ghent University, Gent 9000, Belgium;

Steven.Vanderstichelen@vub.be

Received 8 August 2018 Revised 26 September 2018 Accepted 31 October 2018

\section{D) Check for updates}

(c) Author(s) (or their employer(s)) 2018. No commercial re-use. See rights and permissions. Published by BMJ.

To cite: Vanderstichelen $S$, Cohen J, Van Wesemael Y, et al. BMJ Supportive \& Palliative Care Epub ahead of print: [please include Day Month Year]. doi:10.1136/ bmjspcare-2018-001632

\section{ABSTRACT}

Objectives Volunteers have an important place in palliative care (PC), positively influencing quality of care for seriously ill people and those close to them and providing a link to the community. However, it is not well understood where volunteers fit into PC provision or how to support them adequately. We therefore chose to describe volunteer roles across care settings through the perspective of those closely involved in the care of terminally ill people.

Methods A qualitative study was conducted using both focus groups with volunteers, nurses, psychologists and family physicians and individual semistructured interviews with patients and family caregivers. Participants were recruited from hospital, home, day care and live-in services.

Results 79 people participated in the study. Two volunteer roles were identified. The first was 'being there' for the dying person. Volunteers represent a more approachable face of care, focused on psychological, social and existential care and building relationships. The second was the 'liaison' role. Volunteers occupy a liminal space between the professional and the family domain, through which they notice and communicate patient needs missed by other caregivers. Patient-volunteer matching was a facilitator for role performance; barriers were lack of communication opportunities with professional caregivers and lack of volunteer coordination.

Conclusion Volunteers complement professional caregivers by (1) occupying a unique space between professionals, family and patients and fulfilling a liaison function and (2) being a unique face of care for patients. Healthcare services and policy can support volunteer role performance by ensuring frequent communication opportunities and volunteer coordination.

\section{INTRODUCTION}

Partly inspired by increasing resource constraints in professional healthcare, some governments, including the Belgian government, are turning to informal care to make up a greater proportion of palliative care (PC) provision, for example, through volunteerism. ${ }^{1-4}$ Volunteers played a major part in the early days of the PC movement and continue to be involved both in the community and in institutional settings. ${ }^{5-7}$ They have been shown to influence positively the quality of care for both terminally ill people and those close to them by reducing stress and offering practical and emotional support and providing a link to the community. ${ }^{68-10}$ Research has widely documented the organisational perspective on volunteering, describing the presence of volunteers, turnover rates, task performance and the training they receive. ${ }^{611-13}$ Studies have also shown that volunteers provide palliative, direct patient care in both dedicated and generalist PC (ie, PC provided by regular caregivers such as hospital specialists, family physicians (FPs), home care nurses, nursing home staff), offering psychosocial, signposting and existential care $^{14}$ while suggesting a potential for supporting professional healthcare by being involved in its organisation. ${ }^{15}$

However, alongside this organisational and economic potential, ${ }^{13} 1617$ the capacity of volunteers to support professional healthcare is shaped by the roles they fulfil in PC. Literature has reported a variety of roles ranging in scope from specific (eg, administration, fundraising) to broader (eg, companionship and support) tasks. ${ }^{18-21}$ Roles can be defined as behaviours, rights, obligations, beliefs, norms or a combination; the role is therefore a complex concept encompassing more than a set of tasks. Studying these 
roles as perceived by all those involved provides a more comprehensive grasp of what volunteers actually do, what they mean to the person who is dying, to family carers and to healthcare professionals and their specific contributions to PC provision. Identifying barriers and facilitators in the performance of these roles allows the development of targeted support frameworks for volunteers and the fine-tuning of recruitment strategies.

Previous research on volunteering roles in PC has often included only the perspectives of volunteers ${ }^{22} 23$ and patients. ${ }^{21}$ Others such as family caregivers, FPs, nurses and psychologists also play a crucial role in the care of people with serious illnesses; roles are not fixed or prescribed, but rather negotiated between individuals and their contexts. ${ }^{24}$

This study therefore aims to explore volunteer roles in the following ways:

1. from the perspectives of all those involved in the treatment of people with serious illnesses,

2. in their contexts (ie, hospital, live-in, day care and home care settings) and

3. in how they are negotiated (ie, descriptions of volunteer tasks, boundaries and barriers to and facilitators of role performance).

\section{METHOD}

\section{Design}

In order to explore the tasks and roles of PC volunteers, we applied a qualitative research design, using a phenomenological epistemology. We conducted focus groups with volunteers and professional caregivers and individual semistructured interviews with patients and family caregivers in Flanders, Belgium. Focus groups were chosen because this method stimulates the exchange of views and opinions through discussion and allows mutual differences or similarities to drive the conversation and salient themes to emerge. However, due to the fragile health of people who are dying and the sensitive nature of the subject, individual semistructured interviews were chosen for them and for family caregivers which allowed every case to be treated as discrete and all participants to speak freely. This article follows the COREQ guidelines for reporting qualitative research. ${ }^{25}$

\section{Definitions}

We define tasks as actions or pieces of work to be performed by one or more people. We define roles as collections or combinations of tasks and boundaries which together represent more than the sum of their parts, with a common overarching function or approach. For the definition of volunteering (see online supplementary appendix I).

\section{Context}

PC in Belgium consists of dedicated and generalist PC services. Dedicated PC services provide support for primary care (eg, palliative home care teams (PHT)), day care for people with specific PC needs or PC units; generalist PC refers to certain hospital departments (such as medical oncology departments) and primary care. This coincides with the organisation of care in most countries.

\section{Participants}

As well as the dying person, we included volunteers, family caregivers, nurses, psychologists and FPs as those most important and most closely involved in their treatment and care. FPs were chosen instead of specialists as they play a central role in every care trajectory and because recruiting specialists for every terminal illness was outside the scope of this study. Care settings were considered based on findings from our previous study ${ }^{14}{ }^{15}$ which identified services in Flanders (Belgium) where volunteers provide palliative and direct patient care. These services were divided into three settings: (1) hospital, (2) home care and (3) live-in and day care facilities (see box 1). Services in Flanders were chosen, because the different Belgian regions (Flanders, Wallonia and Brussels) each have autonomy over various aspects of healthcare in the different language communities (Dutch, French and German speaking), including home care, hospital care and long-term care. The organisation of PC therefore differs on the regional level. Other reasons for exclusion of Wallonia and Brussels include the language difference and the long commutes that would be major barriers for the organisation of and participation in focus groups. Services were selected from existing listings available from the Flemish Agency for Health and Care. $^{26}$

Participants were sampled by contacting the coordinators or administrators of services within each setting. FPs were recruited via local FP networks listed on regional FP association websites. Services and FP networks were contacted by phone or email. On agreeing to participate, potential participants were contacted by phone or email to schedule the interviews and focus groups. Three volunteers dropped out as they no longer had time to participate.

\section{Data collection}

Semistructured interviews were individually conducted with the dying person and with family caregivers. Focus groups were separately conducted for (1) volunteers, (2) nurses and psychologists and (3) FPs. Both took place between March and November 2017. Interviews were conducted by SV; focus groups were moderated by SV, KC and other senior researchers and observed by SV, KC and other junior and senior researchers making field notes. See supplementary online appendix II for interviewer characteristics. Participants were given the option to review their transcripts afterwards, but there were no requests to do this. Topic guides for both interviews and focus groups, consisting of open questions and a set of prompts for each question, 
Box 1 Settings from which participants of focus groups and interviews were selected* $\dagger$

1. Hospital settings

a. Medical oncology departments are hospital departments with a fully established oncology care programme, a hospitalisation programme and a multidisciplinary team focused on oncology.

b. Palliative care units are separate units in (or associated with) hospitals that exclusively provide palliative care.

2. Home care settings

a. Facilities for sitting services organise sitting services by volunteers by day or at night. They send a volunteer to people's homes to keep them company, to give basic care and a sense of security. They offer respite care and function similar to befriending services. $\neq$

b. Palliative home care teams (PHT) are part of the palliative networks, that is, cooperative ventures between different providers and care facilities in a particular region-these are palliative care teams supporting other caregivers in home or replacement home situations, supported by the network's volunteers.

c. Volunteer community home care organisations are organised by the Christian Sickness fund locally and run by volunteers.

3. Live-in and day care facilities§

a. Palliative day care centres provide care and nursing during the day and have a respite care function for carers.

b. Nursing homes offer permanent care and nursing to elderly people.

* Descriptions fully or partially taken from the Agency of Health and Care website. ${ }^{26}$

tFor a comprehensive overview of the organisation of palliative care in Belgium see the KCE report. ${ }^{39}$

$\ddagger$ See Walshe et al (2016). ${ }^{40}$

$\S$ Nursing homes and palliative day care centres were grouped

mainly due to the low number of palliative day care centres $(n=5)$ in Belgium and their functional link with nursing homes.

were developed and reviewed by a team of sociologists (SV, KC, JC, LD) and a psychologist (YVW) (see online supplementary appendix III). Both topic guides focused on some of the following key topics: volunteer tasks, task boundaries, the role of volunteers in PC and the barriers to and facilitators of volunteer care.

\section{Data analysis}

All focus groups and interviews were audio-recorded (with the exception of one interview where recording was refused), transcribed verbatim and analysed by a junior and a senior researcher (SV and $\mathrm{KC}$ ) resulting in a total of 26 transcripts. Analysis followed the QUAGOL method $^{27}$-an inductive approach and iterative process of constant comparison. Data collection and analysis were conducted quasi-simultaneously. Two researchers (SV and $\mathrm{KC}$ ) independently read the transcripts, once without coding and then while openly coding the data. From the open coding of each transcript a corresponding conceptual scheme was drawn. These schemes were compared with each other, resulting in a final conceptual scheme from which a coding tree was constructed (see online supplementary appendix II). This coding tree was then discussed in the research team and modified where necessary. Coding was done by SV and KC in the NVIVO 11 qualitative data analysis software package. The salient and overarching themes that emerged from the data were the foundation for the final thematic framework. Data saturation was assumed when no new information emerged. After the thematic framework was agreed on, quotes were selected, translated and approved by the research team. All participants were given pseudonyms.

\section{RESULTS}

We conducted eight focus groups and 18 semistructured individual interviews. Twenty-eight volunteers attended one of four focus groups and 22 care professionals attended one of four focus groups. Ten patients and nine family caregivers took part in semistructured individual interviews. One family caregiver who did not speak Dutch well refused audio recording; the interview was short and only served to highlight relevant themes in the form of researcher notes. Though initial recruitment targets were not reached for professionals in nursing homes, the research team concluded that data saturation was reached and ended data collection at this point; 79 participants were involved in the study. See tables 1 and 2 for participant characteristics.

Two themes emerged in analysis: (1) the volunteer as the other face of care and (2) the liminal space that volunteers occupy. The first gives insight into the tasks and boundaries of volunteers and both into the roles they perform.

\section{Volunteers as the other face of care}

Volunteers were described in the focus groups and interviews as representing a different approach, the 'other face' of care, which made them approachable and easier to confide in. They focused on building a relationship with the dying person and providing psychological, social and existential care for them and those close to them.

Focus on psychological, social and existential care

Four types of care were ascribed to volunteers: (1) practical, (2) psychological, (3) social and (4) existential. Practical care ranged from serving meals and drinks to transport, sometimes even assistant nursing tasks (eg, lifting, washing, bathroom visits). Most volunteers performed several of these tasks; some specialised in one. Psychological care focused on providing comfort, moral support, being an open and neutral conversation partner who listens to their concerns and providing respite to family caregivers. Social care included dropping by for a chat, keeping the person company and actively listening. Participants from all 
Table 1 Characteristics of participants in focus groups

\begin{tabular}{|c|c|}
\hline $\mathrm{N}$ & 50 \\
\hline Focus groups & 8 \\
\hline Mean duration of focus groups (in minutes) & $72(36-89)$ \\
\hline \multicolumn{2}{|l|}{ Sex } \\
\hline Male & $7(14 \%)$ \\
\hline Female & $43(86 \%)$ \\
\hline \multicolumn{2}{|l|}{ Age } \\
\hline$<50$ & $0(0 \%)$ \\
\hline $50-59$ & $3(6 \%)$ \\
\hline $60-69$ & $9(18 \%)$ \\
\hline $70+$ & $1(2 \%)$ \\
\hline Unknown & $37(74 \%)$ \\
\hline \multicolumn{2}{|l|}{ Employment status } \\
\hline Retired & $21(42 \%)$ \\
\hline Employed & $22(44 \%)$ \\
\hline Unknown & $7(14 \%)$ \\
\hline \multicolumn{2}{|l|}{ Discipline } \\
\hline Volunteer (four focus groups) & $28(56 \%)$ \\
\hline PC nurse (two focus groups) & $4(8 \%)$ \\
\hline PC psychologist (two focus groups) & $6(12 \%)$ \\
\hline FP (two focus groups) & $12(24 \%)$ \\
\hline \multicolumn{2}{|l|}{ Years of working experience } \\
\hline$\leq 1$ & $0(0 \%)$ \\
\hline $1-2$ & $5(10 \%)$ \\
\hline $3-5$ & $6(12 \%)$ \\
\hline $6-10$ & $13(26 \%)$ \\
\hline $10-15$ & $6(12 \%)$ \\
\hline$>15$ & $3(6 \%)$ \\
\hline Unclear & $17(34 \%)$ \\
\hline \multicolumn{2}{|l|}{ Setting* } \\
\hline Hospital & $12(24 \%)$ \\
\hline PHT & $11(22 \%)$ \\
\hline $\mathrm{NH}$ & $8(16 \%)$ \\
\hline PDC & $7(14 \%)$ \\
\hline FPs & $12(24 \%)$ \\
\hline
\end{tabular}

*Hospital settings include palliative care units and medical oncology departments.

FPs, family physicians; NH, nursing home; PC, palliative care; PDC, palliative day care centre; $\mathrm{PHT}$, palliative home care teams.

groups described a volunteer as someone the dying person can talk to while patients and family caregivers indicated that they helped normalise their situation and combat social isolation. Existential care aims to maintain the existential and spiritual well-being of the person who is dying and includes talking about life and death, existential anxiety (ie, concerns relating to identity, purpose and being) and religious beliefs. Neither patients nor their family caregivers mentioned existential care; however, volunteers and professional caregivers emphasised its importance.

L: $\quad$ Our [volunteers] presence, er, broadens their capabilities somewhat, because, I think it's often the case that nurses are only content when they have succeeded
Table 2 Characteristics of participants in interviews

\begin{tabular}{|c|c|}
\hline N & $19 *$ \\
\hline Interviews & 18 \\
\hline Mean duration of interviews (in minutes) & $42(21-98) \dagger$ \\
\hline \multicolumn{2}{|l|}{ Sex } \\
\hline Male & 7 \\
\hline Female & 12 \\
\hline \multicolumn{2}{|l|}{ Age } \\
\hline$\leq 29$ & 1 \\
\hline $30-39$ & 0 \\
\hline $40-49$ & 1 \\
\hline $50-59$ & 3 \\
\hline $60-69$ & 5 \\
\hline $70-79$ & 2 \\
\hline $80-89$ & 3 \\
\hline $90+$ & 1 \\
\hline Unknown & 3 \\
\hline \multicolumn{2}{|l|}{ Participant } \\
\hline Patient & 10 \\
\hline Family caregiver & 9 \\
\hline \multicolumn{2}{|l|}{ Illness } \\
\hline Cancer & 15 \\
\hline CHF‡ & 1 \\
\hline Dementia§ & 2 \\
\hline Parkinson's & 1 \\
\hline Heart thrombosis & 1 \\
\hline Cerebral infarction & 1 \\
\hline \multicolumn{2}{|l|}{ Settingी } \\
\hline Hospital & 7 \\
\hline PHT & 6 \\
\hline $\mathrm{NH}$ & 3 \\
\hline PDC & 2 \\
\hline \multicolumn{2}{|c|}{$\begin{array}{l}\text { *One interview was conducted with two participants (husband and } \\
\text { wife). }\end{array}$} \\
\hline \multicolumn{2}{|c|}{$\begin{array}{l}\text { †One interview was not recorded. This interview was short, but the } \\
\text { exact duration is unknown. The calculation of the mean duration of } \\
\text { interviews excluded this interview. }\end{array}$} \\
\hline \multicolumn{2}{|l|}{ ¥Chronic heart failure. } \\
\hline \multicolumn{2}{|l|}{ §Including Alzheimer's. } \\
\hline \multicolumn{2}{|c|}{$\begin{array}{l}\text { IHospital settings include palliative care units and medical oncology } \\
\text { departments. }\end{array}$} \\
\hline \multicolumn{2}{|c|}{$\begin{array}{l}\text { MOD, Medical Oncology Department; NH, nursing home; PCU, palliative } \\
\text { care unit; PDC, palliative day care centre; PHT, palliative home care } \\
\text { teams. }\end{array}$} \\
\hline
\end{tabular}

in the medical. 'The patient feels no pain, has these complaints and I have been able to, er, tend to them etcetera.' And due to the fact that we're also there, they are obligated to also pay attention to the other side of their job.

Interviewer: Can you give an example of this other side of their job?

L: $\quad$ Yes, I consider it the attention to spiritual care. If we- I wouldn't say if we did not introduce it, but that attention comes, is provided more by the volunteers. And 
because of that, they also consider it more often. [...] I notice that, er, many volunteers, because of that attention that they have and are allowed to give and are able to give to patients, they actually introduce a sort of culture, into which the nurses then also follow.

- FG 1: Volunteers (hospital); L (man, retired, volunteer in palliative care unit (PCU) for 8 years)

Volunteers, patients, family and professional caregivers identified strict professional and legal boundaries around practical care tasks. Legal boundaries relate to problems of liability and prohibit volunteers from performing nursing care and household tasks; however, exceptions occurred. FPs and volunteers both indicated that volunteers should not be part of multidisciplinary care team meetings which should have strict legal and professional boundaries placing volunteers entirely outside the medical and nursing domain, something valued by both volunteers and family caregivers.

Marie: In all other clinics care is provided, healing is done. And volunteers are not allowed into that domain. While, here, they just- medication is only for nurses, right?

Interviewer: Right.

Marie: You receive medication, painkillers, that little device that- volunteers don't touch it.

Interviewer: No, no, no.

Marie: They don't even look at it. She's there for- 'do you want anything? Are you hungry? Some of this? Let's go for a walk, the weather's good. What do you say?' If you'd like to have a chat, etcetera.

-I7: $\quad$ Marie (patient in PCU, woman, 83 y/o, stomach tumour, housewife, ex-volunteer);

[discussing the involvement of nurses in intervision meetings]

M: $\quad$ It became too medical I found, and in the end, we [volunteers] have a different function.

D: Ah okay, yeah, yeah.

E: The point is that we don't meddle in the medical. And the point is that they [nurses] focus exclusively on the practical, well, at least focus a lot on the medical.

-FG 2: $\quad$ volunteers (PHTs); M (woman, 64 y/o, volunteer in PHT for 12 years); D (man, $65 \mathrm{y} / \mathrm{o}$, volunteer in PHT for 6 years); E (woman, 69 y/o, volunteer in PHT for 6 years)

Psychological, social and existential care tasks were subject to ethical and professional boundaries. References to discretion emphasised respecting the trust and privacy of the dying person and not being confrontational. Balancing intimacy and distance was cited as a crucial exercise. Professional care givers indicated that volunteers should not cross the line when providing psychological guidance. However, these boundaries were never strictly defined.

Because volunteers were 'other' and excluded from medical and professional tasks, they could engage the dying person through practical tasks in ways that created opportunities for psychological, social and existential care provision. They consistently emphasised that the immediate psychological needs of the person took priority over any practical task they may be involved in and were valued by all participants for the psychological and social care they provided.

MI: $\quad$ And also that the direct care for patients is priority. Er, so you're, you're busy in the kitchen with who knows what, but you hear from the nurse that, er, someone is anxious, er, wishes for someone to be near, wishes- you drop everything. There's always two of us, so you can discuss with your colleague- can you take over for a minute-

Interviewer: Uhuh.

MI: $\quad$ to be there, er, to try to alleviate that immediate need of that moment for that patient.

MA: because that's very important.

MI: $\quad$ I think that's very important.

- FG 1: volunteers (hospital); MI (woman, retired, volunteer in PCU); MA (woman, retired, volunteer in PCU for 25 years)

\section{Building relationships}

This approach, combined with frequent close contact with patients, allowed volunteers to form a different sort of personal relationship with them from that of the professionals. This affinity for forming relationships was described as a key strength of volunteers throughout discussions with all participant groups and was at the centre of the first volunteering role that emerged from the data: 'being there'.

Practical tasks such as serving meals or drinks were indicated by volunteers as a way to check in with the dying person and as an opening to be with them, sit down and have a conversation. Patients described volunteers doing little things for them that made a difference for example, going for walks, granting specific meal requests or making pancakes.

Anneke: There's even a volunteer who, on Valentine, bakes pancakes for everyone.

Interviewer: Really? 
Anneke: Yes.

Interviewer: Cool.

Anneke: And she had baked cupcakes at home as well.

Interviewer: Right.

Anneke: A cupcake with a little heart and your name on it for everyone, brought it here for everyone. She made the pancakes here on the spot.

Interviewer: Oh, that's cool.

Anneke: Yes, absolutely.

- I6: Anneke (patient in PCU, woman, 77 y/o, lung cancer, retired secretary)

'Being there' also helped combat the social isolation associated with being ill. Both volunteers and professional caregivers described deep personal conversations between volunteers and the person who is dying but also mentioned the value of light day-to-day conversations. Family caregivers emphasised the value of having a volunteer to listen to them vent frustrations and talk about things unrelated to the patient and their illness.

Fien: Also, yes, those people [volunteers] are made for that, actually. You can listen to them and you can talk to them and you loosen up when- Because, with other people I immediately think, 'well, I might be complaining'. And because you- my world is set in that apartment-[...] These people are sort of neutral, you understand? I can talk to her a lot, but she doesn't talk to me a lot. She does about things aside from (husband). If I want to talk to her about a trip or something, that's different. A different thing from- right?

Interviewer: Right, right, right.

Fien: But when it concerns (husband) and the illness, she listens to me. Or she'll come in and say 'how's your week?' Then she listens.

- I14: $\quad$ Fien(family caregiver for husband with Parkinson's, woman, 64 y/o)

\section{The liminal space of volunteers}

Whereas the first theme tells us what volunteers represent and what they mean to the dying person, the second explains the emergence of this other face and helps us locate volunteers and the roles they fulfil in a discrete space between professional and family caregivers and the dying person. They are not professional caregivers and do not consider themselves as suchstrict professional and legal boundaries exclude them from this domain; neither are they family or social acquaintances. They traverse and act within both the professional and family domains, but do not belong to either of them; they occupy a liminal space-a term borrowed from anthropological literature, traditionally used to denote the middle stage of rites, periods in time or physical locations between thresholds, where one is neither in the previous nor in the following stage or place but rather in a fluid, malleable place that enables new practices to emerge. ${ }^{28}$

Volunteers are distant enough for the person who is dying not to feel for them the emotional responsibility that they might feel towards those closer to them, but close enough for them to speak to frankly about their condition and concerns. This lower threshold for engagement creates opportunities for volunteers to be the voice of the dying person and provides the basis for continuity of communication which would be impossible if they were fully part of either the professional or the family domain.

Sabine: And if there's anything, you'll more readily, with a volunteer, they have time to talk to you. And you'll say something and they'll- 'oh I'll talk to a nurse about that.'

Interviewer: Uhuh.

Sabine: You notice that.

Interviewer: Right, right, right, right.

Sabine: See, you'll say something and they, but they'll tell you

Interviewer: Yeah.

Sabine: We'll discuss it with the nursing staff, yes.

Interviewer: So they often signal.

Sabine: Yes, yes, yes, they do that.

Interviewer: oh, yes, okay.

Sabine: If there's anything, they'll, er, they'll pass it on.

Interviewer: Yeah.

Sabine: And that's what's nice about it.

- I8: $\quad$ Sabine (patient in PCU, woman, 69 y/o, throat tumour, retired nurse)

The second role that emerges from our data we are therefore calling the 'liaison role'. Volunteers appeared to serve a signposting function, in which they picked up on and communicated to nursing staff the needs and wishes of the dying person, ranging from simple preferences and concerns to anxiety, pain, discomfort and even problems in their households. Nurses and psychologists indicated that they depended on volunteers for this, particularly in home-care, where volunteers visit alone. To avoid embarrassment or being a nuisance to nurses, the dying person could be more comfortable opening up to a volunteer, who represented a 'different face' of care, was located outside the medical domain and took an open, neutral approach. Volunteers therefore sometimes functioned as an advocate for the person who is dying and the close relationship that sometimes emerged between them emphasises the importance of this liaison role.

AM: $\quad$ Sometimes you feel, no, sometimes you feel the opposite I think. Like, 'why don't you pass this on' 
Interviewer: So, in fact, they sometimes see you as a link between-

AM: $\quad$ Yes.

Interviewer: the care- the other caregivers

AM: $\quad$ Things they're afraid to say, yes, yes.

MA: $\quad$ But also because many patients are also worried about nurses' time. They don't want to burden the nurses for too long. $[\ldots]$

AM: $\quad$ I think it's rather something else. Like, 'if I tell the nurse this', sorry to put it in this way-

MA: Uhuh.

AM: $\quad$ But 'she might be angry at me and she still has to care for me.' I've already noticed that a few times, like, 'if I whine and complain too much, well then I'll be the difficult patient here.'

MA: $\quad$ yes, uhuh.

AM: I've noticed that a few times. And for those things, they come to us.

- FG 1: volunteers (hospital); AM (woman, volunteer for 20 years, 3 years in PCU); MA (woman, retired, volunteer in PCU for 25 years)

The possibilities inherent in this relationship contribute to the concept of customised care, a notion emphasised by specialist PC professionals as encompassing their approach to PC and defined as care provided according to the needs and wishes of the person who is dying and those close to them.

RI: Well. I think you need to know the volunteer a little bit to know who fits in which family or who would mean the most there.

$[\ldots]$

RI:

yeah, it's necessary to know each other a bit.

IN: $\quad$ This situation is so complex, we'll put an experienced volunteer here, haha, right?

RI: $\quad$ yes, yes, yes, yes.

IN: $\quad$ Or in this case, well here I can put anyone, we'll put that new volunteer here, this is a nice start, a good first situation.

AM: uhuh.

KA: $\quad$ Yes.

IN: $\quad$ So that is customised care.

$[\ldots]$

AM: Well, also to insert that quality of, of not putting yourself as a volunteer in the foreground.

Interviewer: Uhuh.

AM:

And I think that's when nice customized care can result from it, when, when, yeah, when volunteers can sense that- in this situation, this patient needs this at this moment.

Interviewer: Yes.

KA: $\quad$ Yes.

DE: $\quad$ Yes, it's also customized to the patient-

AM: $\quad$ Yes.

IN: Yes.

DE: $\quad$ and the family

KA: $\quad$ Yes.

AM: $\quad$ and their surroundings.

-FG 6: nurses and psychologists (PHT); RI (woman, palliative care nurse in PHT); IN (woman, nurse and coordinator of PHT); KA (woman, psychologist and volunteer coordinator of PHT); DE (woman, psychologist and volunteer coordinator of PHT); AM (woman, palliative care nurse in PHT)

\section{Barriers to and facilitators of volunteer role performance}

Communication, support, coordination and the extent to which the dying person and the volunteer matched each other were important factors influencing volunteer role performance.

Lack of communication opportunities between volunteers and nurses to pass on the concerns of the dying person was indicated as a barrier to the liaison role of volunteers. Lack of regular volunteer briefings and lack of communication opportunities among volunteers were also indicated to disrupt the flow of communication between and among volunteers and nurses, leading to confusion and misunderstandings. Conversely, where these things were present, participants indicated that they facilitated the volunteer liaison role.

LI: $\quad$ I still think more communication.

RO: Yes.

LI: $\quad$ But I, I think the problem for us is also, with us the nurses work- two nurses work, er, 2 days in the week, one works 3 days. Er, the occupational therapist, er, er, Monday, Wednesday and the week after on Wednesday, Friday. So, it's a constant change of people. A lot has to be done and settled in between. And then I think that the communication, I feel, falls short. With daily affairs-

E: $\quad$ Yes.

LI: that you're not aware of-

RO: $\quad$ Yes.

LI: $\quad$ and that's, er, sometimes very annoying.

E: $\quad$ Yes.

LI: $\quad$ And no one is to blame, it's also due to organisation but I often encounter that.

E: $\quad$ Yes.

LI: $\quad$ And I think it's a shame because it results in a bunch of- 
E: $\quad$ Yes.

LI: $\quad$ yeah, confusion and, and-

E: $\quad$ Emotion.

LI: $\quad$ and sometimes misunderstandings.

- FG 4: volunteers (PDC); LI (woman, 52 y/o, volunteer in PDC for 7 years); RO (woman, $74 \mathrm{y} / \mathrm{o}$, volunteer in PDC for 7 years); $\mathrm{E}$ (man, $61 \mathrm{y} / \mathrm{o}$, volunteer in PDC for 16 years)

Lack of support and coordination for the volunteers impeded their role of 'being there' and the development of the relationship with the dying person. Volunteers often experience direct and indirect bereavement themselves and lack of supervision can complicate their processing of such challenging experiences. Lack of a volunteer coordinator or clear division of responsibilities within the organisation were indicated to increase uncertainty and to impact negatively on the day-to-day functioning of volunteers. However, when support and coordination were present, participants indicated they facilitated volunteer role performance.

RI: $\quad$ And when they have difficult things there, then they do have to be able to talk about it with the nurse: 'I've come across this and there's this, and that's ok but I have difficulties with it'

AM: $\quad$ Yes.

RI: $\quad$ They need a sounding board like 'I understand that you- but they- I shouldn't say have a more difficult relationship, but these people have lived together like this for forty years. They are not going to change that now near the end of life'-

Interviewer: Yeah.

RI: $\quad$ That you can help put that into context and that they can find strength in that, like, okay, that's just how it is there.

$[\ldots]$

RI: But that they receive support of that nurse through reporting, communicating, yes.

Interviewer: Yeah, yeah, yeah.

KA: Yes, that's very important.

- FG 6: nurses and psychologists (PHT); RI (woman, palliative care nurse in PHT); AM (woman, palliative care nurse in PHT); KA (woman, psychologist and volunteer coordinator of PHT)

Patient-matching based on personal compatibility and the needs and wishes of the patient facilitated role performance by volunteers and lowered the threshold to opening up. In palliative home care, this is facilitated by exploratory home visits by a PC nurse and the opportunity for volunteers to refuse patients and vice versa and in nursing homes and day care settings by scheduling which allows patient and volunteer to become familiar with each other.

M: $\quad$ Yes, so when starting here you fill in a volunteer form. Sorry for talking so much haha. And we can indicate there, for example, 'I don't want dementia patients, I don't want children.' Right, we will construct our own profile a bit and then when there's a request for a volunteer somewhere, the nurse there will check if they can match it. That is done with care.

$[\ldots]$

E: I have the impression that the nurse, aside from choosing with care who ends up with a family, that they also look at the personalities, also that of the volunteer. And those of the patient or family.

M: $\quad$ Yes, I think so-

- FG 2: volunteers (PHT); M (woman, 64 y/o, volunteer in PHT for 12 years); $\mathrm{E}$ (woman, $69 \mathrm{y} / \mathrm{o}$, volunteer in PHT for 6 years)

\section{DISCUSSION}

\section{Main findings}

Volunteers were found to represent an 'other', more approachable 'face of care' and to occupy a liminal space between and overlapping the professional and the family domains. They were found to perform two roles: 'being there' and 'liaison'. The main barriers to performing these roles were a lack of communication opportunities with nursing staff, a lack of support in dealing with difficult situations and a lack of coordination in the care setting. Volunteer-patient matching was an important facilitator.

\section{Strengths and weaknesses}

To our knowledge, this study is the first to conceptualise the volunteer space and to offer distinct and detailed volunteer role descriptions that maintain an internal flexibility. Roles are defined by a multifaceted approach and goal, but not a priori defined by how that goal should be reached. Furthermore, we believe this to be the first study to approach the subject from such a broad multidisciplinary and multicontextual perspective which includes volunteers, the person who is dying, family caregivers, FPs, psychologists and nurses from three distinct types of care settings. The potential for social desirability in responses, inherent in qualitative research, is offset by the wide range of participants included. Because interviews were conducted almost exclusively in cancer cases, it is possible that experiences specific to other illness trajectories were missed.

\section{Interpretation}

The themes of volunteers as the other face of care and the liminal space they occupy between the professional 
and family domains define the role of volunteer as distinct from and complementary to that of professionals. We believe that this liminal space-which only volunteers appear to traverse-is precisely what makes volunteers and the care they provide valuable. The concept of liminality, indicating a fluid, malleable space between and connecting two conceptually rigid and mutually exclusive domains, ${ }^{28}$ lends itself well to understanding the volunteer position in PC because it allows for non-discrete categories. In anthropology, liminality has been used to indicate moments (eg, coming of age rites), periods (eg, periods between history-shaping events or transformations) or physical spaces (eg, airports) in which identities, institutions, cultures or locations are in flux, but from which new ones may emerge. ${ }^{29}$ Such a space, conceptually, fits the volunteer position, from which they provide complementary care according to continuously changing needs of the patient, relatives, professionals and situations.

The role of being there corroborates the finding of other studies that presence is a central aspect of volunteer support in $\mathrm{PC},{ }^{80-32}$ through which meaningful encounters with patients emerge. ${ }^{31} 33-35$ The analytical categories reported in this paper resonate with a previous study's findings of volunteers 'being with' and 'doing for' patients, ${ }^{36}$ describing a relational dynamic between volunteers and patients similar to our findings indicating volunteers used practical tasks ('doing for') as a means to perform their role of being present with patients ('being with'). Literature also reports several themes connected to being there ${ }^{30}$ which we also found important: neutrality and openness, customised care and patient-centredness, developing a close bond with the person who is dying, facilitating intimate conversations and active listening. The findings that volunteers considered themselves and their role as separate from nursing and medical professionals and that volunteer roles are entirely complementary to professional care provision may assuage existing concerns among professionals regarding volunteers in PC taking on professional roles and performing nursing tasks. ${ }^{37} 38$ While volunteers did occasionally perform assistant nursing tasks—a finding also published elsewhere ${ }^{14}$-it appears that the legal boundaries and presence of leadership and coordination for volunteers functioned as checks on boundary crossing and facilitated volunteers to perform their own roles.

Aside from the fundamental scientific usefulness of this framework of liminal space, being there and liaison as a theoretical lens through which to understand PC volunteering across and within care services, our results also point to practical measures to improve PC volunteering. First, a clear conceptualisation of the volunteer's position as relational provides a basis to assess whether a service is providing specific support and infrastructure to optimise the volunteer's performance and some pointers as to how to provide it. It is furthermore a basis for the development of volunteer screening frameworks-potentially alleviating recruitment problems identified in previous research ${ }^{14}$-and training modules regarding specific skill requirements for the role of being there and of liaison. Second, the barriers and facilitators identified in this study suggest several practical things that can be done to optimise volunteer role performance such as (1) appointing volunteering coordinators responsible for managing and leading volunteers; funding for an appointed volunteer coordinator could be included in government subsidies (nurses may be considered for this position as our results indicate that they work most closely with volunteers), (2) increasing the access of volunteers to nurses and psychologists to facilitate signposting, continuity of information, processing of difficult situations and to reduce volunteer uncertainty, (3) implementing patient-matching methods suitable to the setting that are sensitive to the preferences of both the person who is dying and the volunteer and (4) avoiding broadening task performance to include the tasks of professional staff. Results indicate that volunteers are able to perform their roles precisely because they are not professionals, are not considered professionals and are not used as professionals. Trends towards substitution of paid staff may therefore compromise quality of care provision, waste resources and increase volunteer turnover. While healthcare systems may differ in the organisation of PC, the inclusion of multiple perspectives from diverse care settings and the corroboration of our findings by international literature suggests that these recommendations are relevant for PC volunteering across regional or national borders.

While this study has highlighted volunteer task boundaries and barriers for volunteer role performance, the limitations of volunteer roles are still unclear, for example, what the boundaries of volunteer confidentiality are and whether volunteer presence is desirable or effective in sensitive and distressed end-oflife scenarios. Case studies of difficult end-of-life situations involving volunteers may provide important insights into such issues. Finally, this study has focused on direct patient care volunteering. However, indirect and non-care related volunteering may also fulfil important roles within the context of PC. Future research may therefore also consider exploring these aspects of volunteering.

\section{CONCLUSION}

PC volunteers occupy a unique space between professionals, the person who is dying and those close to them and offer care that is distinct from but complementary to that provided by professionals. Their roles of being there and liaison help fill the gaps that exist between professionals and family and their position makes them crucial contributors to customised care. Tailored support and infrastructure, for which we make several practical recommendations, are necessary to support this position. We also offer a conceptual lens that may 
be useful to policymakers and healthcare services to shape the volunteer workforce and to researchers to study volunteers within a wide range of PC service settings. The volunteer position and roles outlined in this article are a first step in shaping focused recruitment and support efforts for healthcare services.

Acknowledgements Lenzo Robijn, Else-Gien Statema, Ellen Vanderstichelen, Kim Beernaert and Aline De Vleminck helped with the conducting some of the focus groups either as observers or as moderators. Jane Ruthven provided language editing of the manuscript. All volunteers, nurses, oncological coaches, psychologists, family physicians and coordinators who agreed to participate in one of the eight focus groups. All family physicians from the family physicians' department at Ghent university who agreed to participate in a discussion to reflect on the difficulties with recruiting FPs. All patients and family caregivers who agreed to participate in interviews for this study.

Contributors All authors were involved in the conception and design of this study. SV and KC carried out all qualitative data collection, analysis and interpretation. SV wrote the paper. All authors were involved in revising the article critically. All authors approved the final version of the manuscript.

Funding This work was supported by the Agency for Innovation by Science and Technology (IWT) as part of the INTEGRATE-project (SBO-IWT 140009).

Competing interests None declared.

Patient consent Not required.

Ethics approval The proposal for this study was submitted for approval to the commissions of medical ethics of the university hospital of Brussels (leading) and the university hospital of Ghent (local) (Ref. B.U.N. 143201630093). Approval from both commissions was granted on 30 January 2017.

Provenance and peer review Not commissioned; externally peer reviewed.

Data sharing statement The data of this study are kept by the first author and are available on request.

\section{REFERENCES}

1 Arno PS, Levine C, Memmott MM. The economic value of informal caregiving. Health Aff 1999;18:182-8.

2 Knickman JR, Snell EK, The SEK. The 2030 problem: caring for aging baby boomers. Health Serv Res 2002;37:849-84.

3 Help the Hospices. Volunteer value - a pilot survey. UK Hospices, 2006.

4 Fast J, Keating N, Otfinowski P, et al. Characteristics of family/friend care networks of frail seniors. Can J Aging 2004;23:5-19.

5 Abel EK. The hospice movement: institutionalizing innovation. Int J Health Serv 1986;16:71-85.

6 Morris S, Wilmot A, Hill M, et al. A narrative literature review of the contribution of volunteers in end of life care services. 2012.

7 Bruera E, Higginson I, Ripamonti C, et al. Textbook of palliative medicine, 2006.

8 Luijkx KG, Schols JM. Volunteers in palliative care make a difference. J Palliat Care 2009;25:30-9.

9 McKee M, Kelley ML, Guirguis-Younger M, et al. It takes a whole community: the contribution of rural hospice volunteers to whole-person palliative care. J Palliat Care 2010;26:103-11.

10 Block EM, Casarett DJ, Spence C, et al. Got volunteers? Association of hospice use of volunteers with bereaved family members' overall rating of the quality of end-of-life care. J Pain Symptom Manage 2010;39:502-6.
11 Morris SM, Payne S, Ockenden N, et al. Hospice volunteers: bridging the gap to the community? Health Soc Care Community 2017;25:1704-13.

12 Burbeck R, Low J, Sampson EL, et al. Volunteers in specialist palliative care: a survey of adult services in the United Kingdom. J Palliat Med 2014;17:568-74.

13 Claxton-Oldfield S, Claxton-Oldfield J. Should i stay or should i go: a study of hospice palliative care volunteer satisfaction and retention. Am J Hosp Palliat Med 2012;29:525-30.

14 Vanderstichelen S, Houttekier D, Cohen J. Palliative care volunteerism across the healthcare system: a survey study. Palliat Med 2018;32:1233-45.

15 Vanderstichelen S, Cohen J, Van Wesemael Y, et al. Volunteer involvement in the organisation of palliative care: a survey study of the healthcare system in flanders and dutchspeaking Brussels, Belgium. Health Soc Care Community 2018.

16 Hotchkiss RB, Unruh L, Fottler MD. The role, measurement, and impact of volunteerism in hospitals. Nonprofit Volunt Sect Q 2014;43:1111-28.

17 Hotchkiss RB, Fottler MD, Unruh L. Valuing volunteers: the impact of volunteerism on hospital performance. Health Care Manage Rev 2009;34:119-28.

18 Emanuel EJ, Fairclough DL, Slutsman J, et al. Assistance from family members, friends, paid care givers, and volunteers in the care of terminally ill patients. N Engl J Med 1999;341:956-63.

19 Wilson DM, Justice C, Thomas R, et al. End-of-life care volunteers: a systematic review of the literature. Health Serv Manage Res 2005;18:244-57.

20 Handy F, Srinivasan N. Valuing volunteers: an economic evaluation of the net benefits of hospital volunteers. Nonprofit Volunt Sect Q 2004;33:28-54.

21 Faulkner M, Davies S. Social support in the healthcare setting: the role of volunteers. Health Soc Care Community $2005 ; 13: 38-45$.

22 Delaloye S, Escher M, Luthy C, et al. Volunteers trained in palliative care at the hospital: an original and dynamic resource. Palliat Support care 2014:1-7.

23 Phillips J, Andrews L, Hickman L. Role ambiguity, role conflict, or burnout: are these areas of concern for Australian palliative care volunteers? Pilot study results. Am J Hosp Palliat Care 2014;31:749-55.

24 Mead GH. Mind, self, and society. University of Chicago Press,, 1967.

25 Tong A, Sainsbury P, Craig J. Consolidated criteria for reporting qualitative research (COREQ): a 32-item checklist for interviews and focus groups. Int J Qual Health Care 2007;19:349-57.

26 Agentschap Zorg en Gezondheid. Zorgaanbod per domein. 2017. Available: https://www.zorg-en-gezondheid.be/perdomein [Accessed 7 Aug 2017].

27 Dierckx de Casterlé B, Gastmans C, Bryon E, et al. QUAGOL: a guide for qualitative data analysis. Int J Nurs Stud 2012;49:360-71.

28 Turner V. Liminality and Communitas. In:The ritual process: structure and anti-structure. Chicago: Aldine Publishing, 1969: pp. 94-113.

29 Thomassen B. The uses and meanings of liminality. Int Polit Anthropol 2009;2:5-27.

30 Baugher JE. Facing death: buddhist and western hospice approaches. Symb Interact 2008;31:259-84.

31 Goossensen A, Somsen J, Scott R, et al. Defining volunteering in hospice and palliative care in Europe: an EAPC white paper. Eur J Palliat Care 2016;23:184-91.

32 Söderhamn U, Flateland S, Fensli M, et al. To be a trained and supported volunteer in palliative care - a phenomenological study. BMC Palliat Care 2017;16:18.

33 Burbeck R, Candy B, Low J, et al. Understanding the role of the volunteer in specialist palliative care: a systematic review 
and thematic synthesis of qualitative studies. BMC Palliat Care 2014;13

34 Zerwekh JV. The practice of presencing. Semin Oncol Nurs 1997;13:260-2.

35 Fredriksson L. Modes of relating in a caring conversation: a research synthesis on presence, touch and listening. J Adv Nurs 1999;30:1167-76.

36 Dodd S, Hill M, Ockenden N, et al. 'Being with' or 'doing for'? How the role of an end-of-life volunteer befriender can impact patient wellbeing: interviews from a multiple qualitative case study (ELSA). Support Care Cancer 2018;26:3163-72.

37 Claxton-Oldfield S, Gibbon L, Schmidt-Chamberlain K. When to say "yes" and when to say "no": boundary issues for hospice palliative care volunteers. Am J Hosp Palliat Care 2011;28:429-34.

38 Berry P, Planalp S. Ethical issues for hospice volunteers. Am J Hosp Palliat Care 2008;25:458-62.

39 Keirse E, Beguin C, Desmedt M. Organisatie van palliatieve zorg in België. Heal Serv Res (HSR) Brussel Fed Kenniscentrum voor Gezondheidszorg 2009.

40 Walshe C, Algorta GP, Dodd S, et al. Erratum to: protocol for the End-of-Life Social Action Study (ELSA): a randomised wait-list controlled trial and embedded qualitative case study evaluation assessing the causal impact of social action befriending services on end of life experience. BMC Palliat Care 2016;15:98. 